\title{
25 Research Soure \\ Quantitative Real Time PCR (qPCR) Screening Confirms Babesia Bovis Infections in Cattle in Kenya
}

\author{
Naftaly W. Githaka \\ ILRI: International Livestock Research Institute \\ Richard P. Bishop \\ Washington State University \\ Jan Šlapeta \\ : The University of Sydney School of Veterinary Science \\ David Emery \\ : The University of Sydney School of Veterinary Science \\ Edward K. Nguu \\ University of Nairobi College of Biological and Physical Sciences \\ Esther G. Kanduma ( $\nabla$ ekanduma@yahoo.co.uk) \\ University of Nairobi School of Biological Sciences https://orcid.org/0000-0002-4979-2681
}

\section{Research Article}

Keywords: Babesiosis, Rhipicephalus microplus, Tick-borne diseases, Transboundary diseases, Ticks, Babesia bigemina, Animal disease diagnostics

Posted Date: October 21st, 2021

DOI: https://doi.org/10.21203/rs.3.rs-979686/v1

License: (c) (i) This work is licensed under a Creative Commons Attribution 4.0 International License. Read Full License 


\section{Abstract}

\section{Background}

Among protozoan parasites in the genus Babesia, Babesia bigemina is endemic and widespread in the East African region while the status of the more pathogenic Babesia bovis remains unclear despite the presence of the tick vector, Rhipicephalus microplus which transmits both species. Recent studies have confirmed the occurrence of $R$. microplus in coastal Kenya and although $B$. bovis DNA has previously been detected in cattle blood in Kenya, no surveillance has been done to establish its prevalence. This study therefore investigated the occurrence of $B$. bovis in cattle in Kwale County, Kenya, where $R$. microplus is present in large numbers.

\section{Method}

A quantitative species-specific multiplex Taqman PCR assay targeting two Babesia bovis genes, 18S ribosomal RNA and mitochondriallyencoded cytochrome $b$ and Babesia bigemina cytochrome $b$ gene was used to screen 506 cattle blood DNA samples collected from Kwale County for presence of Babesia parasite DNA.

\section{Results}

A total of 131 animals (25.8\%) were found to have bovine babesiosis. Of these, $87(17.2 \%)$ were positive for B. bovis while $70(13.8 \%)$ had B. bigemina while 26 (5.1\%) were observed to be co-infected with both Babesia species. A total of 61 animals (12.1\%) were found to be infected with $B$. bovis parasites only, while 44 animals $(8.7 \%)$ had $B$. bigemina only. B. bovis infections were detected in 11 sites while $B$. bigemina was detected in 9 out of the 12 sites sampled in three Kwale sub-Counties.

\section{Conclusion}

These findings reveal high prevalence of pathogenic $B$. bovis in a Kenyan area cutting across a busy transboundary livestock trade route with neighboring Tanzania. The Babesia multiplex assay used in this study is specific and can detect and differentiate the two Babesia species and should be used for routine $B$. bovis surveillance to monitor the spread and establishment of the pathogen in other African countries where $B$. bigemina is endemic. Moreover, these findings reveal a potential threat of fatal babesiosis in the absence of endemic stability in the local cattle populations.

\section{Introduction}

Bovine babesiosis, the most economically important vector-borne disease of livestock globally is caused by protozoan parasites Babesia bovis and Babesia bigemina that are transmitted by tick species in the sub-genus Boophilus [1]. The disease causes major economic losses through animal mortality, poor growth rates, reduced milk yields in sick or recovered animals, and direct costs of tick control and disease treatment [2]. In Africa, B. bigemina is endemic and currently more widespread than $B$. bovis reflecting the distribution of the indigenous tick vector Rhipicephalus decoloratus which is more widely distributed in Africa, although Rhipicephalus evertsi evertsi is also a known vector [3]. Rhipicephalus microplus which is an efficient vector of $B$. bovis has become established in mainland Tanzania with evidence of displacement of the native $R$. decoloratus [4]. The tick has only been recorded in a small foci in coastal Kenya [5, 6]. However, in the past 15 years, $R$. microplus, which is the definitive host for both $B$. bovis and $B$. bigemina has been confirmed to occur in several countries in West Africa [7-9] Central Africa [10,11] and recently in East Africa [12-16]. The impact of this dispersal on the occurrence of $B$. bovis and the risk of pathogenic babesiosis is currently unknown.

Clinical bovine babesiosis presents with significant haemolysis of the red blood cells, continuous fever, anaemia and often haemoglobinuria, which colours the urine reddish brown giving the disease the common name 'red water'. Infections associated with $B$. bovis are often acute or subacute, have a shorter time course with more severe nervous symptoms rapidly leading to death, or a protracted recovery rate in non-fatal cases [17]. Acute disease can cause nervous symptoms such as 'pedalling' movements and aggressive behaviour. In dairy cows, abortion and reduced or complete loss of milk (agalactia) are early signs of Babesia infection. Redwater causes high mortality and morbidity in susceptible livestock, especially in exotic and cross breed cattle. Mortality rates of $30 \%$ for B. bigemina and $70-$ $80 \%$ for the more pathogenic B. bovis infections have been observed. Indigenous breeds of cattle can also be greatly affected by the less pathogenic $B$. bigemina under conditions of poor health or nutrition, a situation that is common in many vast areas of Africa, including Kenya [2]. Babesiosis caused by B. bigemina is characterized by low parasitemias of less than $1 \%$. In contrast, $B$. bovis infection has a high parasitemia of greater than $10 \%$, frequently with sequestration of infected red blood cells in cerebral capillaries resulting in symptoms which are often fatal. Cattle that recover from primary acute babesiosis, either naturally or after treatment, remain persistently infected and serve as a source of future transmission $[17,18]$. 
There is paucity of data on the status and occurrence of $R$. microplus outside the coastal counties in Kenya. Therefore, $R$. decoloratus which is widely distributed in all agriculturally productive areas of eastern, central, Rift Valley and western Kenya [19] has been regarded as the major vector of bovine babesiosis in Kenya. Previously, McLeod and Kristjanson [20] predicted that $70 \%$ of Kenyan cattle were at risk from babesiosis and anaplasmosis with estimated annual economic losses amounting to $\$ 6.9$ million per year. Co-infestation of animals with multiple tick species is typical, so multiple co-infection with tick-transmitted pathogens and significant disease burdens are frequently detected.

Diagnosis of redwater in Kenya is mainly through observation of clinical signs and because of the characteristic haematuria, microscopic examination of blood smears for Babesia parasites is usually not performed. Given the limited records of R. microplus in Kenya to date, bovine babesiosis has always been attributed to the more ubiquitous $B$. bigemina vectored by $R$. decoloratus. However, the recent confirmation of the occurrence of $R$. microplus in coastal Kenya by Kanduma et al. [13] portends the existence of B. bovis. Babesia bovis DNA has been reported previously in cattle blood in Kenya [21,22]. The use of molecular tests increases the sensitivity for detection and enables differentiation of $B$. bovis from other Babesia parasites. Kim et al. [23] and Zhang et al. [24] previously developed and validated highly sensitive quantitative qPCR Taqman probes for detecting, quantifying and differentiating $B$. bovis from B. bigemina. In this study, we used these probes to investigate the occurrence of $B$. bovis in Kenya considering the recent reports of $R$. microplus in the local cattle populations.

\section{Materials And Methods}

\section{Study site}

A cross-sectional study was conducted in May 2019 in 12 sites in Kwale County, Kenya (Figure 1). The County is situated along the Kenyan coastline neighbouring the Indian Ocean on the East and South East and Tanzania on the South West. The County has a tropical type of climate with an average temperature of $23^{\circ} \mathrm{C}$ with a high of $25^{\circ} \mathrm{C}$ in March and a low of $21^{\circ} \mathrm{C}$ in July. Annual precipitation is less than $800 \mathrm{~mm}$ with the coastal parts of the County receiving greater than $1000 \mathrm{~mm}$ of precipitation per year, while a majority of the central to west areas receive around $500-750 \mathrm{~mm}$. Rainfall is bi-modal with a short rain season from October to December and a long rain season from April to July. Detailed geo-climatic characteristics of the County have previously been described [13].

\section{Cattle blood sampling}

A total of 506 adult cattle were randomly sampled across 12 sites located in three sub-Counties namely, Matuga, Msabweni and Lunga Lunga (Figure 1). Blood samples were collected in EDTA and vacutainer plain tubes by jugular vein puncture, transported in cool boxes to the regional laboratory in Kwale and refrigerated at $4^{\circ} \mathrm{C}$. The samples were later transported to the International Livestock Research Institute (ILRI) Laboratories in Nairobi for analysis and long-term storage. Sera was collected in $2 \mathrm{ml}$ cryotubes and stored at $-20^{\circ} \mathrm{C}$ for subsequent serological detection of circulating tick-borne pathogen antibodies. Two $(\mathrm{ml})$ aliquots of the EDTA blood were preserved at $-80^{\circ} \mathrm{C}$ for future use. The remaining EDTA blood sample was stored at $-20^{\circ} \mathrm{C}$ for use in molecular detection of tick-borne pathogens.

\section{Whole blood genomic DNA isolation}

Whole cattle blood collected in EDTA tubes was thawed and thoroughly mixed by gentle rocking. Whole blood genomic DNA was isolated from $300 \mu \mathrm{l}$ of whole cattle blood using the Promega Wizard® genomic DNA purification kit (Promega Corporation, Wisconsin, USA) by following manufacturer's protocol. DNA quantity and purity were measured with a nanodrop spectrophotometer "Nanodrop2000" (ThermoScientific, United States of America). The DNA was stored at $-20^{\circ} \mathrm{C}$ until use.

\section{Detection and quantification of Babesia DNA}

A multiplex quantitative Taqman probe assay targeting two $B$. bovis and one B. bigemina genes was used to detect Babesia DNA. One $B$. bovis primer and probe set targeted the nuclear 18S rDNA [23] while the other targeted the mitochondrial cytochrome $b$ gene [24]. The $B$. bigemina primers and probe were derived from the cytochrome $b$ gene. Details of the primer and probe sequences used in the multiplex assay are listed in Table 1. The qPCR was conducted in a QuantStudio 5 detection system (Thermo Fisher Scientific, Massachusetts, USA). The $20 \mu \mathrm{L}$ reactions included $10 \mu \mathrm{L}$ of $2 \times$ Universal Probe qPCR Master Mix (New England Biolabs, Massachusetts, USA), $0.8 \mu \mathrm{L}$ of each oligonucleotide primer, $0.2 \mu \mathrm{L}$ of the fluorescence-labelled probe, and $3 \mu \mathrm{L}$ of genomic DNA template. Temperature cycling parameters were $95.0^{\circ} \mathrm{C}$ for $3 \mathrm{~min}$ followed by 45 cycles of $95 \circ \mathrm{C}$ for $10 \mathrm{~s}$ and $54 \circ \mathrm{C}$ for $25 \mathrm{~s}$. Each PCR run included a B. bovis and B. bigemina positive control sample and a no-template PCR grade water sample as negative control. The cycle quantification (Cq) scores corresponding to the PCR cycle number at which the amplification curve of each sample intersected the threshold line was recorded for each sample.

\section{Standardization and construction of qPCR calibration curves}


To evaluate the performance of the three primer sets, $3 \mu \mathrm{L}$ of $B$. bovis control DNA sample (48ng/ $\mu \mathrm{l})$ isolated from an in vitro culture and a B. bigemina positive control DNA sample $(17 \mathrm{ng} / \mu \mathrm{l})$ isolated from blood of an infected calf at the Tick Fever Centre (TFC), Queensland Department of Agriculture, Australia, were 10 -fold serially diluted from $10^{-1}$ to $10^{-8}$. The diluted DNA was then amplified using a multiplexed assay of three primer and probe sets (B. bovis $18 \mathrm{~S}, B$. bovis cytochrome $b$ and $B$. bigemina cytochrome $b$; Table 1 ). Resulting data was analysed using the QuantStudio design and analysis software version 2.6.0. To generate the calibration curves, the cycle quantification (Cq) scores for the diluted samples were determined based on a default threshold of $0.02 \Delta \mathrm{Rn}$ then plotted against corresponding DNA dilution. The efficiency (E) of the primer sets expressed as a percentage of each of the individual qPCR assay was calculated from the slope of the respective standard curve. The coefficient of correlation $\left(R^{2}\right)$ of each standard curve was also determined using the QuantStudio analysis software.

\section{Data analysis}

The data was exported to Ms Excel where the mean and range of $\mathrm{Cq}$ scores were calculated. Paired nonparametric Wilcoxon signed rank test was applied in GraphPad Prism (V 9.2.0) to compare the Cq levels detected by the two B. bovis genes employed. Statistical significance was determined when $\mathrm{P}<0.05$. Kappa coefficient was calculated in Excel to evaluate the degree of agreement between the $18 \mathrm{~S}$ and cytochrome $b$ genes in $B$. bovis detection. A XY scatter plot of Cq values detected was generated using GraphPad Prism. A bar graph of distribution of positive cases across sampled sites was constructed.

\section{Results}

\section{Babesia primer statistical parameters, standard curves and efficiency}

A summary of the statistical parameters, standard curves and efficiencies of the primers sets used in the multiplex assay are shown in Table 2 and Figure 2. The lowest Cq value detected by the $B$. bovis $18 \mathrm{~S}$ primer pair at the lowest serial dilution of $10^{-1}$ was 23.096 while the cytochrome $b$ detected a Cq of 16.879 . The $B$. bigemina cytochrome $b$ primers detected a Cq of 23.537 at the lowest dilution of $10^{-1}$. The $B$. bovis $18 \mathrm{~S}$ primers returned a high $\mathrm{Cq}$ value of 44.872 at $10^{-7}$ dilution while the cytochrome $b$ returned a high of 34.847 at a dilution of $10^{-6}$. The $B$. bigemina cytochrome $b$ primers returned a high of 33.387 at a dilution of $10^{-4}$. Cq values obtained with the $B$. bovis cytochrome $b$ primers were significantly lower (Wilcoxon matched pairs signed rank test $p<0.0001$ ) than corresponding values obtained with18S (Table 2).

The B. bovis 18 S primer set had an efficiency of $96.7 \%$. Its standard curve had a slope of -3.404 and a correlation coefficient ( $\left.R^{2}\right)$ of 0.982 . The $\mathrm{Y}$-Intercept was 19.89 . The $B$. bovis cytochrome $b$ primers had an efficiency of $90.3 \%$, a slope -3.579 and a $\mathrm{R}^{2}$ of 1.0 and a $\mathrm{Y}$-Intercept of 13.19. The $B$. bigemina set had an efficiency of $96.7 \%$, a slope of -3.404 and a $R^{2}$ of 0.997 and a $Y$-Inter:20.102. The standard curve, slope, $\mathrm{R}^{2}$ and efficiencies of each primer set as determined from the $\mathrm{Cq}$ values of the serially diluted standard solutions are shown in Figure 2 . The $B$. bovis $18 \mathrm{~S}$ and cytochrome $b$ which were labelled with different fluorescence dyes were not detected in the $B$. bigemina control and neither was the $B$. bigemina cytochrome $b$ detected in the $B$. bovis control included in each PCR run. Thus, the primer sets employed were speciesspecific for $B$. bovis and $B$. bigemina as no cross-reaction was observed with the respective controls. In all the PCR reactions carried out, a no-template water sample was included as a negative control to rule out false positives due to cross-contamination.

Detection and quantification of $B$. bovis and B. bigemina DNA

The qPCR primer sets employed in this study allowed for species-specific detection and quantification of B. bovis and B. bigemina DNA present in the screened blood samples. Since the efficiency parameters of the primers were within the recommended limits (Table 2 and Figure 2), all samples that returned $\mathrm{Cq}$ values of $<45$ for the $B$. bovis $18 \mathrm{~S}$ primers with a good quality amplification plot were regarded as positives since the corresponding $\mathrm{Cq}$ values obtained with the cytochrome $b$ primers for the same samples were lower (Additional file Table $\mathrm{S} 1$ ). For the $B$. bovis and B. bigemina cytochrome $b$ primer sets, all samples that returned Cq values of $<42$ with a good quality amplification plot were also regarded as positives. A total of 131/506 returned Cq values that met these criteria and were thus classified as positive for either B. bovis or B. bigemina or both. Detectable amplifications with the B. bovis $18 \mathrm{~S}$ primers were observed in 39 samples, while a total of 87 samples resulted in detectable amplicons using the $B$. bovis cytochrome $b$ primers. A list of the 131 field samples and their corresponding Cq values is shown in Additional file Table S1. The range distribution of the Cq levels detected by the three assays is shown in Figure 3. The highest $\mathrm{Cq}$ value obtained with the field samples using the $B$. bovis $18 \mathrm{~S}$ was 44.68 and the lowest was 12.95 with a mean Cq value of 36.55 (SD \pm 5.995$)$. The $B$. bovis cytochrome $b$ returned a high $\mathrm{Cq}$ value of 41.158 and a low of 29.914 with a mean Cq value of 35.37 (SD \pm 2.997 ). The $B$. bigemina cytochrome $b$ primers returned a high of 41.38 and a low of 20.956 with a mean of 33.152 (SD \pm 3.766). A comparison of 33 pairs of $B$. bovis Cq values obtained with both $18 S$ and cytochrome $b$ primers using Wilcoxon matched pairs 
signed rank test revealed that the cytochrome $b$ values were significantly lower than corresponding values obtained with18S ( $p<0.0001$ ) (Table 2). No detectable amplification was observed in 375 of the screened DNA samples.

\section{Prevalence of B. bovis and B. bigemina infection}

A total of 506 cattle blood samples were screened for presence of both $B$. bovis and B. bigemina. The distribution of the number of positive cases across the sampled sites is shown in Table 3 and Figure 4 . The overall bovine babesiosis prevalence rate was 25.8\% (131/506). Of the 131 Babesia positive animals, 87 were found to be infected with $B$. bovis indicating a prevalence of $17.2 \%$ (87/506), while 70 were positive for $B$. bigemina giving a prevalence of $13.8 \%(70 / 506)$ and a further $26(5.1 \%)$ had mixed infections of both $B$. bovis and $B$. bigemina. Using the $B$. bovis $18 \mathrm{~S}$ and cytochrome $b$ primers employed in this study, a total of 61 animals (12.1\%) were found to have $B$. bovis infection while 44 animals (8.7\%) were positive for B. bigemina only. The $18 \mathrm{~S}$ B. bovis primers detected 39 positive cases (7.7\%) while the $B$. bovis cytochrome $b$ primers detected $81(16 \%)$ positive cases. There was a weak agreement between the $B$. bovis $18 S$ and cytochrome $b$ detection assays (Kappa $=0.36)$.

Babesia bovis infections were detected in 11 sites while B. bigemina was detected in 9 out of the 12 sites sampled. The highest $B$. bovis prevalence was 5.3\% (27/506) observed in Vanga (Lunga Lunga sub-County) while the lowest was 0.5\% (3/506) observed in Kiwambale (Lunga Lunga sub-County) and Tangini (Msambweni). The highest prevalence of B. bigemina was 3.4\% (17/506) observed in Miaji Farm. There were no cases of either B. bovis or B. bigemina in Mwanjaba (Msambweni sub-County.

\section{Discussion}

Following from the recent demonstrations of $R$. microplus in southern-eastern Kenya, this study confirmed the presence of $B$. bovis DNA in cattle blood from the same region. This was necessary to instigate monitoring and control measures because the economic burden of ticks and tick-borne diseases in Africa [2] and also globally is high [1]. Climate change has contributed to expanded range of tick vectors increasing the risk of tick-borne diseases in Africa [25]. Bovine babesiosis is one of the four major livestock diseases that is prevalent in Kenya [21, 26-30]. Until recently, bovine babesiosis in Kenya was presumed to be caused by $B$. bigemina, transmitted by $R$. decoloratus which is endemic in many regions in Kenya [19]. Recent recordings of $R$. microplus in Kwale [13], indicated an urgent need for surveillance of $B$. bovis to update epidemiological data on bovine babesiosis.

Screening of the cattle samples with two B. bovis and one B. bigemina specific probes, we observed that $B$. bovis was present in $17.2 \%$ $(87 / 506)$ of the animals while $13.8 \%(70 / 506)$ of the samples were positive for $B$. bigemina. Co-infections with the two Babesia spp were observed in 26 (5.1\%) of the animals screened (Table 3). This is the first study to report significant occurrence of the pathogenic $B$. bovis in Kenya and East African region. The findings indicate that $B$. bovis infections do occur in significant numbers in this region but are probably disregarded in most studies screening for tick pathogens because of the belief that only the endemic B. bigemina is present.

In this study, the highest prevalence of $B$. bovis was observed in Vanga located within the Lunga Lunga sub-County which borders Tanzania. There is a livestock market in Tanga, a port city in Northeast Tanzania and at the Kenya border post at Lunga Lunga where cattle from Tanzania are purchased by Kenyans from neighbouring counties. There is a holding area at Lunga Lunga and another in Msambweni in Kwale along the major highway from the border for keeping recently acquired animals that are in transit to neighbouring counties. The Lunga Lunga market is frequented by Kenyan traders from as far as Tana River County while some are from Somalia. The extensive movement and transborder trade of infected and tick-infested animals is regarded as the major driving factor that is responsible for introduction of tick vectors and Babesia spp into new areas [17]. A similar pattern of transboundary cattle trade contributing to the spread of R. microplus and possibly its associated pathogens has been reported in Central and West Africa where animal movement across national boundaries is common [11]. The finding of high prevalence of the pathogenic $B$. bovis reported in this study indicates a possible threat of fatal bovine babesiosis across eastern Africa countries where most cattle would be lacking endemic stability to the disease. These observations together with the recent confirmation of occurrence of $R$. microplus in Kenya provide a rationale to implement urgent surveillance to determine and monitor the spread of $B$. bovis. Effective measures should also be instituted to control the spread of $R$. microplus to limit establishment of $B$. bovis babesiosis.

The molecular tests used have added both reliability and sensitivity to the detection of $B$. bovis infections in Kenya. Previously, for an active $B$. bovis infection, a diagnosis was confirmed by the presence of two pairs of small pear-shaped bi-lobed parasites in giemsa-stained blood smears[17]. However, the presence of $B$. bigemina in a blood smear may not necessarily indicate clinical babesiosis, as symptoms can be due to resurgence of a chronic infection. In Kenya, diagnosis of redwater is confirmed by observation of the characteristic red urine and therefore microscopic examination of blood smears is seldom performed. In national diagnostic and research laboratories, detection of circulating $B$. bigemina antibodies is used for disease surveillance [26, 27, 31]. Molecular PCR techniques have been used to detect and 
differentiate Babesia parasites with high sensitivity and specificity [32-34]. Based on PCR amplification and sequencing of the $B$. bovis spherical body protein-4 (SBP-4) gene, Moumouni et al. [22] previously reported a B. bovis prevalence of $12.3 \%$ and $23.7 \%$ in Kajiado and Machakos Counties, respectively. Babesia bigemina was found to be more prevalent in Kajiado. Using the reverse line blot (RLB) assay targeting the V4 hypervariable region of Babesia rRNA, Njiiri et al., [21] reported a B. bovis prevalence of $2.2 \%$ in Busia County, Western Kenya. In this study we used a well validated Taqman probe multiplex assay based on B. bovis 18S [23], B. bovis cytochrome $b$ [24] and $B$. bigemina cytochrome $b$ [24] that can detect, differentiate $B$. bovis from $B$. bigemina and has the potential to quantify levels of infection. High specificities and efficiencies of above $96 \%$ were observed with these primer and probe sets (Figure 2) confirming the efficiency and usefulness of these assays in detecting, quantifying, and discriminating B. bovis infections (Figure 2, Table 2). In our study, a total of 61 animals $(12.1 \%)$ were found to have $B$. bovis parasites only using both the $18 \mathrm{~S}$ and cytochrome $b$ primers while 44 animals $(8.7 \%)$ had $B$. bigemina only. There was a weak agreement between the two B. bovis detection assays (Kappa $=0.36$ ). In 33 blood samples where $B$. bovis was detected by both probes used, the $18 \mathrm{~S}$ gene was detected in significantly lower copies compared cytochrome $b$ (Wilcoxon matched pairs signed rank test $(\mathrm{p}<0.0001)$. The difference in sensitivities between the $B$. bovis $18 \mathrm{~S}$ and cytochrome $b$ primers may be due to differences in abundance of the two gene products. The $B$. bovis genome has been shown to contain three rRNA operons [35]. Although information on the number of mitochondria in Babesia parasites is lacking, some apicomplexan parasites, such as Toxoplasma gondii and Plasmodium falciparum have been reported to have only a single mitochondrion per parasite [36]. The mitochondrial DNA of Plasmodium falciparum comprises approximately 20 copies of a 6 kbp linear genome per cell $[37,38]$ encoding three protein coding genes including cytochrome $b$ [35]. Therefore, the quantities detected by different genes could reflect the gene copies per individual organisms as well as level of parasitaemia which was not determined in this study. More $B$. bovis positive samples were detected with the cytochrome $b$ primers compared to the $18 \mathrm{~S}$ indicating the higher sensitivity obtained by using this gene as compared to the nuclear-encoded $18 \mathrm{~S}$ rRNA gene. Therefore, based on the data obtained in this study and theoretical predictions, the $B$. bovis cytochrome $b$ primers would be the best target for a routine field diagnostic assay. However, it would appear from all these studies that $B$. bovis is well established in Kenya, while its biological vector, $R$. microplus, has also been confirmed to occur [13].

Animals that recover from babesiosis become carriers of babesia parasites for life and can develop the disease again if they undergo physiological stresses such as nutritional restriction or co-infection with another infection. Babesiosis is therefore a costly chronic animal disease in endemic areas, because of frequent resurgence, especially if the animals are experiencing stress [2]. Factors such as animal breed, type of agro-ecological zone (AEZ) and livestock production systems are important risk factors associated with babesiosis infections [27]. Majority of farmers in Kwale County which has an estimated 190,988 zebu cattle and 5,475 dairy crosses [39] practice open grazing system which has previously been shown to be significantly associated with high prevalence of $B$. bigemina infections in Murang'a County in Kenya [27]. Kwale County, which is a gateway to mainland Kenya for livestock purchased from the Tanzanian border market, could be acting as focal source of $B$. bovis infections to the rest of the country.

Ticks and tick-borne diseases are the biggest threat to sustainable cattle production in Kenya which has close to 18 million cattle [40]. Although this study reports high prevalence of $B$. bovis in three sub-Counties in Kwale, the situation in the rest of the country is unknown. The spread and clinical consequences of $B$. bovis infections in Kenya could add severe burdens on survival and productivity of cattle enterprises, especially because of occurrence of multiple co-infections is common, thereby intensifying the impacts of other serious infections such as East Coast fever. Therefore, the demonstration of the parasite at the prevalence revealed indicate its establishment and local transmission. It is recommended that molecular diagnostics including the qPCR used in this study be added to routine surveillance to detect and differentiate the two Babesia parasites with the aim of obtaining a complete picture of the prevailing status of bovine babesiosis in the country. Such dataset is critical in designing disease and vector control programs both locally and for neighbouring countries.

\section{Conclusions}

This study found a high prevalence rate of $B$. bovis in Kwale County with potential to cause disease outbreaks in susceptible animal populations. The Babesia multiplex assay used in this study is specific and can detect and differentiate the two Babesia parasites. The $B$. bovis cytochrome $b$ primers would be the best target for a routine field diagnostic assay. Urgent surveillance and mapping should be undertaken to determine and monitor the spread of $B$. bovis babesiosis and inform the design of effective control measures.

\section{Abbreviations}

EDTA: Ethylenediaminetetraacetic acid; Cq: cycle quantification; DNA: deoxyribonucleic acid; dNTPs: deoxyribonucleotide triphosphates; ILRI: International Livestock Research Institute; rDNA: ribosomal Deoxyribonucleic Acid; qPCR: Quantitative PCR; RLB: reverse line blot; TFC: Tick Fever Centre 


\section{Declarations}

\section{Ethics approval and consent to participate}

Not applicable

\section{Consent for publication}

Not applicable

\section{Availability of data and materials}

All the data sets supporting the conclusions of this article have been presented.

\section{Competing interests}

The authors declare that they have no competing interests.

\section{Funding}

The field sampling and laboratory analysis was supported by the CGIAR research program on Livestock (https://livestock.cgiar.org/). Training in qPCR diagnostics was supported by Australia Awards-Africa through a postdoctoral fellowship to EGK.

\section{Authors' contributions}

NG, EGK, EKN and RPB conceived the research proposal. NG, EGK, EKN and DE developed the research concept. NG and EGK coordinated and carried out field sampling. DE and JŠ designed and supervised the validation of the qPCR assay. EGK, NG and RPB drafted the manuscript. All authors reviewed the manuscript to its current form and approved the final manuscript.

\section{Acknowledgements}

We are very grateful for the permission, support, and facilitation of the Directorate of Veterinary Services, Department of Agriculture, Livestock and Fisheries, Kwale County, Kenya. Much appreciation to the Director, Dr. Mwalonya Hamisi and Sub-County Veterinary Officers; Dr. Mburu, Dr. Umlai M. and Dr. Nyamweya and Animal Health Assistants (AHAs) Emmanuel Nuamawi and Patience Salama who mobilized the farmers and coordinated blood sampling. We acknowledge the technical assistance with animal bleeding offered by Thomas Njoroge, (ILRI). We thank Prof Brian Cooke, James Cook University, Queensland, Australia for provision of B. bovis positive control DNA sample and the Tick Fever Centre, Biosecurity Sciences Laboratory, Department of Agriculture and Fisheries, State of Queensland for provision of $B$. bigemina infected blood for extraction of a positive control sample.

\section{References}

1. Jongejan F, Uilenberg G. The global importance of ticks. Parasitology. 2004;129.

2. Minjauw B, Mcleod A. Tick-borne diseases and poverty Bruno Minjauw and Anni McLeod. Vet Med. 2003;

3. Friedhoff KT. Transmission of Babesia. Babesiosis Domest Anim Man. CRC Press; 1988;23-52.

4. Lynen G, Zeman P, Bakuname C, Di Giulio G, Mtui P, Sanka P, et al. Shifts in the distributional ranges of Boophilus ticks in Tanzania: Evidence that a parapatric boundary between Boophilus microplus and B. decoloratus follows climate gradients. Exp Appl Acarol. 2008;44:147-64.

5. Walker JB. The Ixodid Ticks of Kenya. A Review of Present Knowledge of Their Hosts and Distribution. J Parasitol. Commonwealth Institute of Entomology, 56 Queen's Gate, London, S.W.7.; 1974;61:694.

6. Zulu FP, Okello-Onen J, Punyua D, Essuman S, Malonza MM. A note on the ticks of domestic animals in coast province, Kenya. Insect Sci. its Appl. 1998. p. 163-5.

7. De Clercq EM, Vanwambeke SO, Sungirai M, Adehan S, Lokossou R, Madder M. Geographic distribution of the invasive cattle tick Rhipicephalus microplus, a country-wide survey in Benin. Exp Appl Acarol. Springer; 2012;58:441-52.

8. Adakal H, Biguezoton A, Zoungrana S, Courtin F, de Clercq EM, Madder M. Alarming spread of the Asian cattle tick Rhipicephalus microplus in West Africa-another three countries are affected: Burkina Faso, Mali and Togo. Exp Appl Acarol. Springer; 2013;61:383-6.

9. Kamani J, Apanaskevich DA, Gutiérrez R, Nachum-Biala Y, Baneth G, Harrus S. Morphological and molecular identification of Rhipicephalus (Boophilus) microplus in Nigeria, West Africa: a threat to livestock health. Exp Appl Acarol. Springer; 2017;73:283-96. 
10. Gomes AF, Neves L. Rhipicephalus microplus (Acarina, Ixodidae) in Angola: evidence of its establishment and expansion. Exp Appl Acarol. Springer; 2018;74:117-22.

11. Silatsa BA, Kuiate JR, Njiokou F, Simo G, Feussom JMK, Tunrayo A, et al. A countrywide molecular survey leads to a seminal identification of the invasive cattle tick Rhipicephalus (Boophilus) microplus in Cameroon, a decade after it was reported in Cote d'Ivoire. Ticks Tick Borne Dis. Urban \& Fischer; 2019;10:585-93.

12. Muhanguzi D, Byaruhanga J, Amanyire W, Ndekezi C, Ochwo S, Nkamwesiga J, et al. Invasive cattle ticks in East Africa: morphological and molecular confirmation of the presence of Rhipicephalus microplus in south-eastern Uganda. Parasit Vectors. BioMed Central; 2020;13:165.

13. Kanduma EG, Emery D, Githaka NW, Nguu EK, Bishop RP, Šlapeta J. Molecular evidence confirms occurrence of Rhipicephalus microplus Clade A in Kenya and sub-Saharan Africa. Parasites and Vectors. 2020;13.

14. Mamiro KA, Magwisha HB, Rukambile EJ, Ruheta MR, Kimboka EJ, Malulu DJ, et al. Occurrence of Ticks in Cattle in the New Pastoral Farming Areas in Rufiji District, Tanzania. J Vet Med. 2016;2016:1-5.

15. Damian D, Damas M, Wensman JJ, Berg M. Genetic Relationship between Hard Ticks (Ixodidae) Infesting Cattle from Select Areas of a Wildlife-Livestock Interface Ecosystem at Mikumi National Park, Tanzania. Vector-Borne Zoonotic Dis. 2021;21:191-9.

16. Damian D, Damas M, Wensman JJ, Berg M. Molecular diversity of hard tick species from selected areas of a wildlife-livestock interface ecosystem at mikumi national park, Morogoro Region, Tanzania. Vet Sci. Multidisciplinary Digital Publishing Institute; 2021;8:1-11.

17. Young AS, Morzaria SP. Biology of Babesia. Parasitol Today. Elsevier Current Trends; 1986;2:211-9.

18. Bock R, Jackson L, De Vos A, Jorgensen W. Babesiosis of cattle. Parasitology. 2004;129.

19. Walker A., Bouattour A, Camicas J., Estrada-peña A, Horak I., Latif A., et al. Ticks of domestic animals in Africa: a guide to identification of species. Univ Edinburgh. 2003;227.

20. McLeod A, Kristjanson R. Impact of ticks and associated diseases on cattle in Asia, Australia and Africa. Int. Livest. Res. Inst. eSYS Rep. to ACIAR. 1999.

21. Njiiri NE, Bronsvoort BM de C, Collins NE, Steyn HC, Troskie M, Vorster I, et al. The epidemiology of tick-borne haemoparasites as determined by the reverse line blot hybridization assay in an intensively studied cohort of calves in western Kenya. Vet Parasitol. Elsevier; 2015;210:69-76.

22. Adjou Moumouni PF, Aboge GO, Terkawi MA, Masatani T, Cao S, Kamyingkird K, et al. Molecular detection and characterization of Babesia bovis, Babesia bigemina, Theileria species and Anaplasma marginale isolated from cattle in Kenya. Parasites and Vectors. BioMed Central; 2015;8:496.

23. Kim C, Iseki H, Herbas MS, Yokoyama N, Suzuki H, Xuan X, et al. Development of Taqman-based real-time PCR assays for diagnostic detection of Babesia bovis and Babesia bigemina. Am J Trop Med Hyg. 2007;77:837-41.

24. Zhang B, Sambono JL, Morgan JAT, Venus B, Rolls P, Lew-Tabor AE. An evaluation of quantitative PCR assays (TaqMan® and SYBR Green) for the detection of Babesia bigemina and Babesia bovis, and a Novel fluorescent-ITS1-PCR capillary electrophoresis method for genotyping B. bovis isolates. Vet Sci. Multidisciplinary Digital Publishing Institute; 2016;3:23.

25. Githaka N, Kanduma E, Bishop R. Role of climate and other factors in determining the dynamics of tick and tick-transmitted pathogen populations and distribution in western, central, and eastern Africa-. In: Nuttall P, editor. Clim Ticks Dis. CABl; 2021. p. 486-91.

26. Gachohi JM, Ngumi PN, Kitala PM, Skilton R a. Estimating seroprevalence and variation to four tick-borne infections and determination of associated risk factors in cattle under traditional mixed farming system in Mbeere District, Kenya. Prev Vet Med. Elsevier B.V.; 2010;95:208-23.

27. Gitau GK, Perry BD, Katende JM, McDermott JJ, Morzaria SP, Young AS. The prevalence of serum antibodies to tick-borne infections in cattle in smallholder dairy farms in Murang'a District, Kenya; a cross-sectional study. Prev Vet Med. Elsevier; 1997;30:95-107.

28. Mbogo SK. Epidemiology of ticks and tick-borne diseases in Kenya: Future research needs and priorities. Epidemiol ticks tick-borne Dis Eastern, Cent South Africa Proc a Work Held Harare, 12-13 March 1996. 1996. p. 174.

29. Okuthe OS, Buyu GE. Prevalence and incidence of tick-borne diseases in smallholder farming systems in the western-Kenya highlands. Vet Parasitol. 2006;141:307-12.

30. Wesonga FD, Gachohi JM, Kitala PM, Gathuma JM, Njenga MJ. Seroprevalence of Anaplasma marginale and Babesia bigemina infections and associated risk factors in Machakos County, Kenya. Trop Anim Health Prod. 2017;49:265-72.

31. Tebele N, Skilton RA, Katende J, Wells CW, Nene V, McElwain T, et al. Cloning, characterization, and expression of a 200-kilodalton diagnostic antigen of Babesia bigemina. J Clin Microbiol. 2000;38:2240-7. 
32. Buling A, Criado-Fornelio A, Asenzo G, Benitez D, Barba-Carretero JC, Florin-Christensen M. A quantitative PCR assay for the detection and quantification of Babesia bovis and B. bigemina. Vet Parasitol. Elsevier; 2007;147:16-25.

33. Oliveira-Sequeira TCG, Oliveira MCS, Araujo JP, Amarante AFT. PCR-based detection of Babesia bovis and Babesia bigemina in their natural host Boophilus microplus and cattle. Int J Parasitol. Pergamon; 2005;35:105-11.

34. Lew AE, Dalrymple BP, Jeston PJ, Bock RE. PCR methods for the discrimination of Babesia bovis isolates. Vet Parasitol. Elsevier; 1997;71:223-37.

35. Brayton KA, Lau AOT, Herndon DR, Hannick L, Kappmeyer LS, Berens SJ, et al. Genome sequence of Babesia bovis and comparative analysis of apicomplexan hemoprotozoa. PLoS Pathog. 2007;3:1401-13.

36. Verhoef JMJ, Meissner M, Kooij TWA. Organelle Dynamics in Apicomplexan Parasites. MBio. American Society for Microbiology; $2021 ; 12$.

37. Preiser PR, Wilson RJ, Moore PW, McCready S, Hajibagheri MA, Blight KJ, et al. Recombination associated with replication of malarial mitochondrial DNA. EMBO J. John Wiley \& Sons, Ltd; 1996;15:684-93.

38. Hikosaka K, Kita K, Tanabe K. Diversity of mitochondrial genome structure in the phylum Apicomplexa. Mol Biochem Parasitol. Elsevier; 2013;188:26-33.

39. County Government of Kwale. Kwale County Integrated Development Plan 2018-2022. County Government of Kwale; 2018;

40. FAO. Africa Sustainable Livestock (ASL) 2050 Country Brief: Kenya. 2017.

\section{Tables}

Table 1. Details of qPCR primers used in detection of Babesia parasites

\begin{tabular}{|c|c|c|c|c|}
\hline Target gene & Primer/probe name & Nucleotide sequence & Size & Reference \\
\hline \multirow[t]{4}{*}{ Babesia bovis $18 \mathrm{~S}$} & Forward: S0934_BoF_18S & AGCAGGTTTCGCCTGTATAATG & 22 & [23] \\
\hline & Reverse: S0933_BoR_18S & AGTCGTGCGTCATCGACAAA & 20 & \\
\hline & & \multirow{2}{*}{$\begin{array}{l}\text { FAM-CCTTGTATGACCCTGTCGTACCGTTGG- } \\
\text { BHQ1 }\end{array}$} & \multirow[t]{2}{*}{27} & \\
\hline & S0935_BoP_Kim & & & \\
\hline \multirow[t]{3}{*}{$\begin{array}{l}\text { Babesia bovis Cytochrome } b \\
\text { (cytb) }\end{array}$} & $\begin{array}{l}\text { Forward: } \\
\text { S0936_bovisF160_cytb }\end{array}$ & ATATGTTTGCATTTGCTG & 18 & {$[24]$} \\
\hline & $\begin{array}{l}\text { Reverse: } \\
\text { S0937_bovisR249_cytb }\end{array}$ & CTCCAAACCAATATGAAAG & 19 & \\
\hline & Probe: S0938_bovisPb_cytb & $\begin{array}{l}\text { JOE- CAAACCATAAAGTCATCGGTATATCCTAC- } \\
\text { BHQ1 }\end{array}$ & 29 & \\
\hline \multirow{6}{*}{$\begin{array}{l}\text { Babesia bigemina } \\
\text { Cytochrome } b \text { (cytb) }\end{array}$} & Forward: & GGTCTATTTGGTGGAGTT & 18 & {$[24]$} \\
\hline & bigemF295 & & & \\
\hline & Reverse: & ACAAGACCAAATGCAATT & 18 & \\
\hline & bigemR413 & & & \\
\hline & Probe: & TAMRA-CAATTGTTCTTGGAGCAGCT- BHQ1 & 20 & \\
\hline & bigemPb & & & \\
\hline
\end{tabular}

Table 2. Summary details of the statistics and efficiency parameters of the three primer sets 


\begin{tabular}{|c|c|c|c|c|c|c|c|}
\hline $\begin{array}{l}\text { Sample } \\
\text { Name }\end{array}$ & $\begin{array}{l}\text { Serial dilution } \\
\text { level }\end{array}$ & $\begin{array}{l}\text { DNA } \\
\text { concentration }\end{array}$ & Gene & CT & $\begin{array}{l}\text { Y- } \\
\text { Intercept }\end{array}$ & Slope & Efficiency \\
\hline Bbov1 & $10^{-1}$ & $14.4 \mathrm{ng}$ & B. bovis $18 \mathrm{~S}$ & 23.096 & 19.887 & -3.404 & 96.686 \\
\hline Bbov2 & $10^{-2}$ & $1.44 \mathrm{ng}$ & B. bovis $18 \mathrm{~S}$ & 26.650 & 19.887 & -3.404 & 96.686 \\
\hline Bbov3 & $10^{-3}$ & $144 \mathrm{pg}$ & B. bovis $18 \mathrm{~S}$ & 30.442 & 19.887 & -3.404 & 96.686 \\
\hline Bbov4 & $10^{-4}$ & $14.4 \mathrm{pg}$ & B. bovis $18 \mathrm{~S}$ & 34.005 & 19.887 & -3.404 & 96.686 \\
\hline Bbov5 & $10^{-5}$ & $1.44 \mathrm{pg}$ & B. bovis $18 \mathrm{~S}$ & 37.187 & 19.887 & -3.404 & 96.686 \\
\hline Bbov6 & $10^{-6}$ & $144 \mathrm{fg}$ & B. bovis $18 \mathrm{~S}$ & 39.268 & 19.887 & -3.404 & 96.686 \\
\hline Bbov7 & $10^{-7}$ & $14.4 \mathrm{fg}$ & B. bovis $18 \mathrm{~S}$ & 44.872 & 19.887 & -3.404 & 96.686 \\
\hline Bbov8 & $10^{-8}$ & $1.44 \mathrm{fg}$ & B. bovis $18 \mathrm{~S}$ & Undetermined & 19.887 & -3.404 & 96.686 \\
\hline Bbov1 & $10^{-1}$ & $14.4 \mathrm{ng}$ & B. bovis Cytochrome $b$ & 16.879 & 13.187 & -3.579 & 90.289 \\
\hline Bbov2 & $10^{-2}$ & $1.44 \mathrm{ng}$ & B. bovis Cytochrome $b$ & 22.327 & 13.187 & -3.579 & 90.289 \\
\hline Bbov3 & $10^{-3}$ & $144 \mathrm{pg}$ & B. bovis Cytochrome $b$ & 23.886 & 13.187 & -3.579 & 90.289 \\
\hline Bbov4 & $10^{-4}$ & $14.4 \mathrm{pg}$ & B. bovis Cytochrome $b$ & 27.370 & 13.187 & -3.579 & 90.289 \\
\hline Bbov5 & $10^{-5}$ & $1.44 \mathrm{pg}$ & B. bovis Cytochrome $b$ & 30.973 & 13.187 & -3.579 & 90.289 \\
\hline Bbov6 & $10^{-6}$ & $144 \mathrm{fg}$ & B. bovis Cytochrome $b$ & 34.847 & 13.187 & -3.579 & 90.289 \\
\hline Bbov7 & $10^{-7}$ & $14.4 \mathrm{fg}$ & B. bovis Cytochrome $b$ & Undetermined & 13.187 & -3.579 & 90.289 \\
\hline Bbov8 & $10^{-8}$ & $1.44 \mathrm{fg}$ & B. bovis Cytochrome $b$ & Undetermined & 13.187 & -3.579 & 90.289 \\
\hline Bbig1 & $10^{-1}$ & $51 \mathrm{ng}$ & $\begin{array}{l}\text { B. bigemina Cytochrome } \\
b\end{array}$ & 23.537 & 20.012 & -3.404 & 96.700 \\
\hline Bbig2 & $10^{-2}$ & $5.1 \mathrm{ng}$ & $\begin{array}{l}\text { B. bigemina Cytochrome } \\
b\end{array}$ & 26.746 & 20.012 & -3.404 & 96.700 \\
\hline Bbig3 & $10^{-3}$ & $510 \mathrm{pg}$ & $\begin{array}{l}\text { B. bigemina Cytochrome } \\
\text { b }\end{array}$ & 29.944 & 20.012 & -3.404 & 96.700 \\
\hline Bbig4 & $10^{-4}$ & $51 \mathrm{pg}$ & $\begin{array}{l}\text { B. bigemina Cytochrome } \\
b\end{array}$ & 33.387 & 20.012 & -3.404 & 96.700 \\
\hline Bbig5 & $10^{-5}$ & $5.1 \mathrm{pg}$ & $\begin{array}{l}\text { B. bigemina Cytochrome } \\
b\end{array}$ & Undetermined & 20.012 & -3.404 & 96.700 \\
\hline Bbig6 & $10^{-6}$ & $510 \mathrm{fg}$ & $\begin{array}{l}\text { B. bigemina Cytochrome } \\
\text { b }\end{array}$ & Undetermined & 20.012 & -3.404 & 96.700 \\
\hline Bbig7 & $10^{-7}$ & $51 \mathrm{fg}$ & $\begin{array}{l}\text { B. bigemina Cytochrome } \\
\text { b }\end{array}$ & Undetermined & 20.012 & -3.404 & 96.700 \\
\hline Bbig8 & $10^{-8}$ & $5.1 \mathrm{fg}$ & $\begin{array}{l}\text { B. bigemina Cytochrome } \\
b\end{array}$ & Undetermined & 20.012 & -3.404 & 96.700 \\
\hline
\end{tabular}

Table 3. Distribution of Babesia positive blood across the study sites 


\begin{tabular}{|c|c|c|c|c|c|c|c|c|c|}
\hline \multicolumn{3}{|l|}{ Sampling site } & \multicolumn{7}{|c|}{ Total number of Babesia positive samples by gene } \\
\hline Sub-County & $\begin{array}{l}\text { Sampling } \\
\text { site }\end{array}$ & $\begin{array}{l}\text { Number } \\
\text { of } \\
\text { animals } \\
\text { sampled }\end{array}$ & $\begin{array}{l}\text { B. bovis } \\
\text { positive } \\
\text { by } 18 \mathrm{~S} \\
\text { (including } \\
\text { mixed } \\
\text { infection) }\end{array}$ & $\begin{array}{l}\text { B. bovis } \\
\text { positive by } \\
\text { cytochrome } \\
\text { b (including } \\
\text { mixed } \\
\text { infection) }\end{array}$ & $\begin{array}{l}\text { B. bovis } \\
\text { positive by } \\
\text { both } 18 S \& \\
\text { cytochrome } \\
b \text { (including } \\
\text { mixed } \\
\text { infection) }\end{array}$ & $\begin{array}{l}\text { B. bovis } \\
\text { (Single } \\
\text { infection) } \\
\text { by both18S } \\
\& \\
\text { cytochrome } \\
b\end{array}$ & $\begin{array}{l}B . \\
\text { bigemina } \\
\text { including } \\
\text { mixed } \\
\text { infection }\end{array}$ & $\begin{array}{l}B \text {. } \\
\text { bigemina } \\
\text { (Single } \\
\text { infection) }\end{array}$ & $\begin{array}{l}\text { Mixed } \\
\text { infection }\end{array}$ \\
\hline Matuga & Matuga & 13 & 2 & 4 & 5 & 2 & 6 & 3 & 3 \\
\hline Matuga & Miaji farm & 40 & 1 & 4 & 4 & 2 & 17 & 15 & 2 \\
\hline Matuga & Kipabane & 43 & 3 & 8 & 8 & 5 & 4 & 1 & 3 \\
\hline Matuga & $\begin{array}{l}\text { Kichaka } \\
\text { Simba }\end{array}$ & 107 & 0 & 17 & 17 & 17 & 0 & 0 & 0 \\
\hline Msambweni & Tangini & 59 & 3 & 2 & 3 & 2 & 10 & 9 & 1 \\
\hline Msambweni & Majiboni & 32 & 1 & 3 & 3 & 3 & 0 & 0 & 0 \\
\hline Msambweni & Ukunda & 28 & 1 & 1 & 1 & 0 & 3 & 2 & 1 \\
\hline Msambweni & Mwanjaba & 10 & 0 & 0 & 0 & 0 & 0 & 0 & 0 \\
\hline $\begin{array}{l}\text { Lunga } \\
\text { Lunga }\end{array}$ & $\begin{array}{l}\text { Shimoni } \\
\text { Kidimu }\end{array}$ & 34 & 4 & 9 & 10 & 4 & 10 & 4 & 6 \\
\hline $\begin{array}{l}\text { Lunga } \\
\text { Lunga }\end{array}$ & Kiwambale & 33 & 3 & 2 & 3 & 2 & 2 & 1 & 1 \\
\hline $\begin{array}{l}\text { Lunga } \\
\text { Lunga }\end{array}$ & Shimoni & 32 & 5 & 6 & 6 & 5 & 3 & 2 & 1 \\
\hline $\begin{array}{l}\text { Lunga } \\
\text { Lunga }\end{array}$ & Vanga & 75 & 16 & 25 & 27 & 19 & 15 & 7 & 8 \\
\hline Total & & 506 & 39 (7.7\%) & $81(16 \%)$ & $87(17.2 \%)$ & $61(12 \%)$ & $\begin{array}{l}70 \\
(13.8 \%)\end{array}$ & 44 (8.7\%) & $\begin{array}{l}26 \\
(5.1 \%)\end{array}$ \\
\hline
\end{tabular}

\section{Figures}




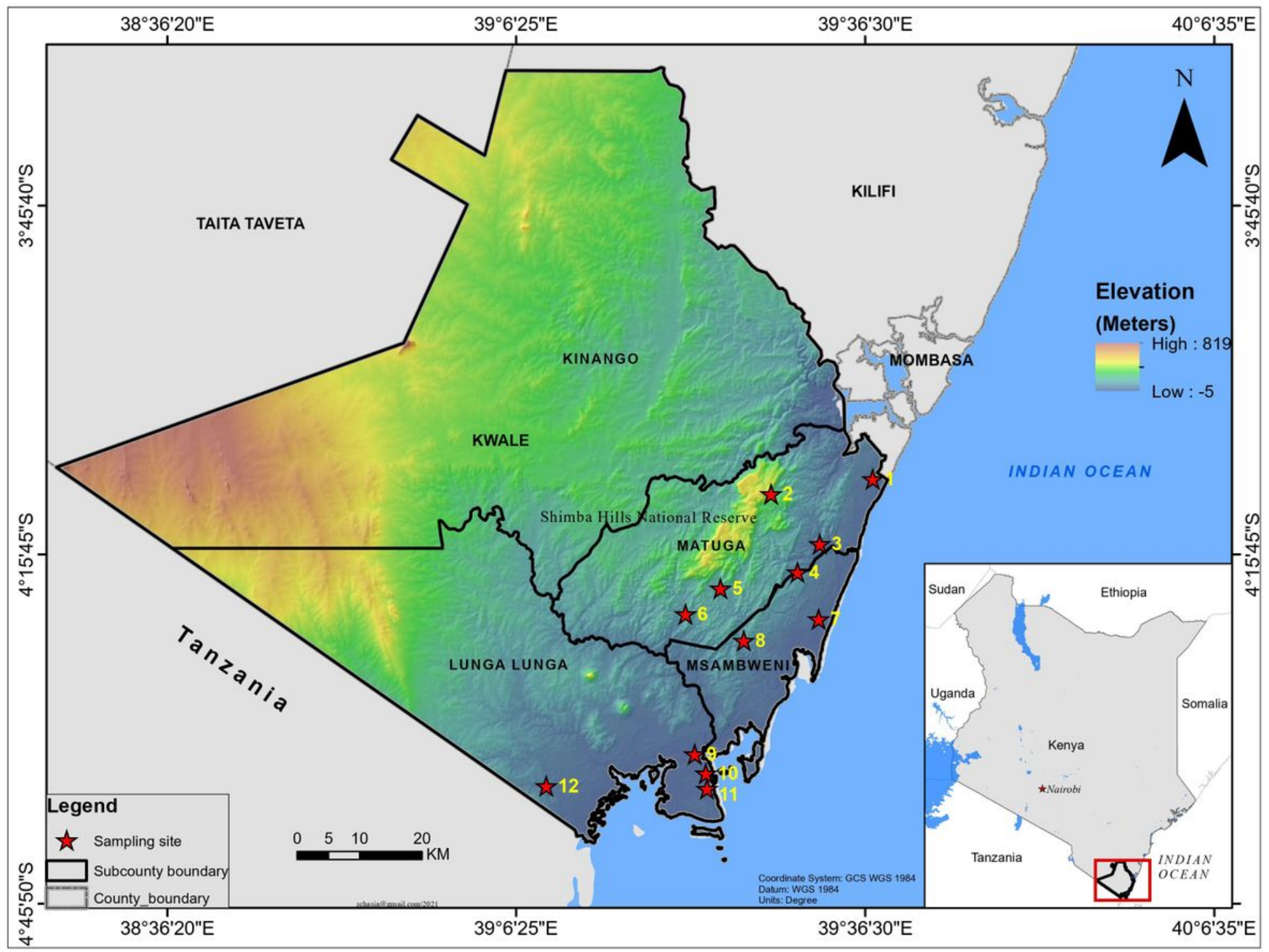

\section{Figure 1}

Map of Kwale County showing the 12 localities where 507 cattle were sampled (shown in numbers). The localities were: - 1). Miaji farm $(n=40), 2)$. Matuga $(n=13), 3)$. Ukunda $(n=28), 4)$. Mwanjaba $(n=10), 5)$. Kipabane $(n=43), 6)$. Kichaka simba $(n=107), 7)$. Majiboni $(n=32)$, 8). Tangini $(n=59), 9)$. Shimoni Kidimu $(n=34), 10)$. Shimoni $(n=32), 11)$. Kiwambale $(n=33), 12)$. Vanga $(n=75)$ 


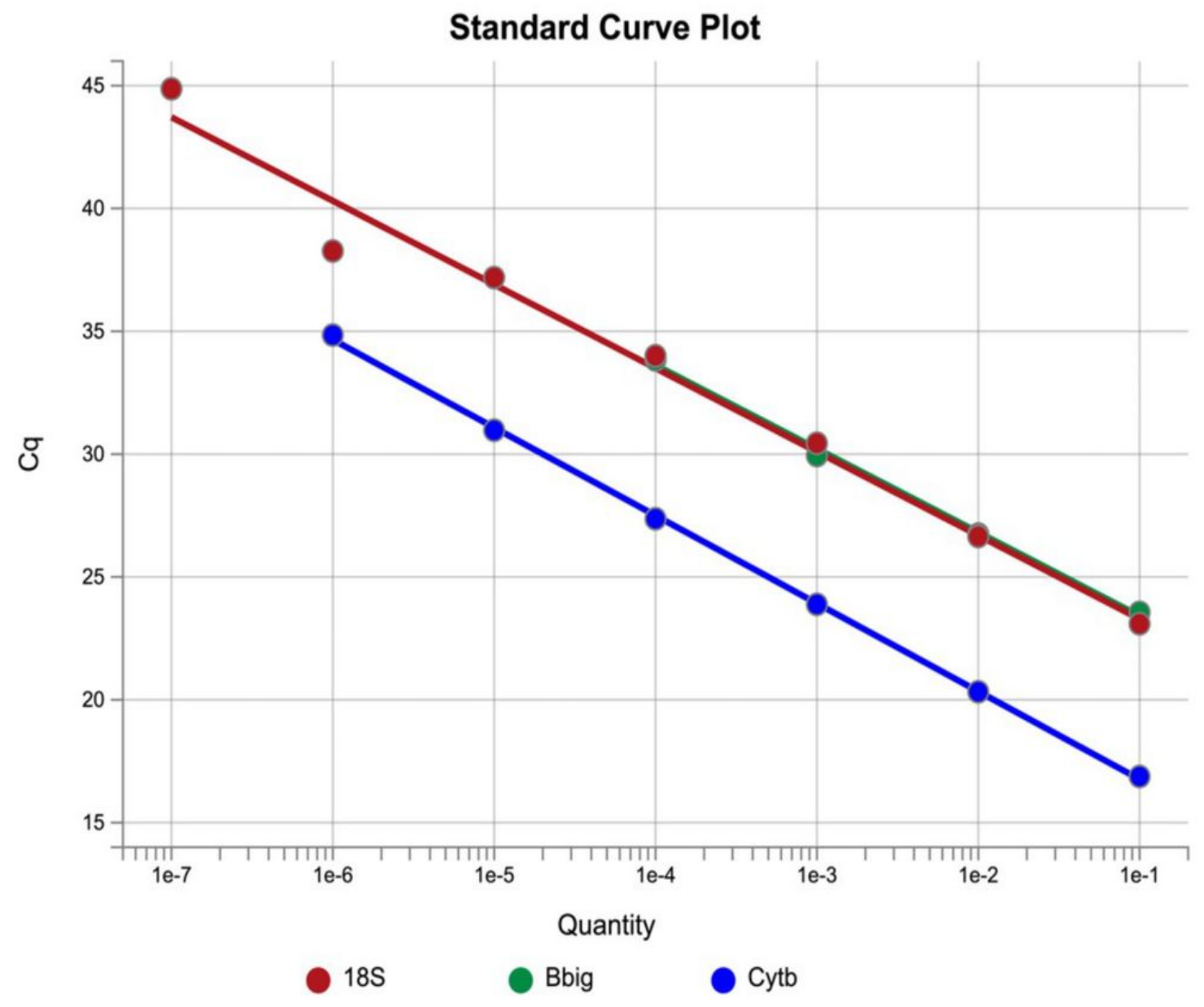

Target: Bbig Slop:-3.404 $R^{2}: 0.997 \quad$ Y-Inter: $20.012 \quad$ Eff\%: $96.7 \quad$ Error: 0.121

Target: Cytb Slop: $-3.579 \quad R^{2}: 1 \quad$ Y-Inter: $13.187 \quad$ Eff\%: $90.289 \quad$ Error: 0.034

Target: $18 S$ Slop: $-3.404 \quad R^{2}: 0.982 \quad$ Y-Inter: 19.887 Eff\%: 96.686 Error: 0.207

\section{Figure 2}

Standard curves of the three primer and probe sets used in the detection of Babesia parasites in the current study 


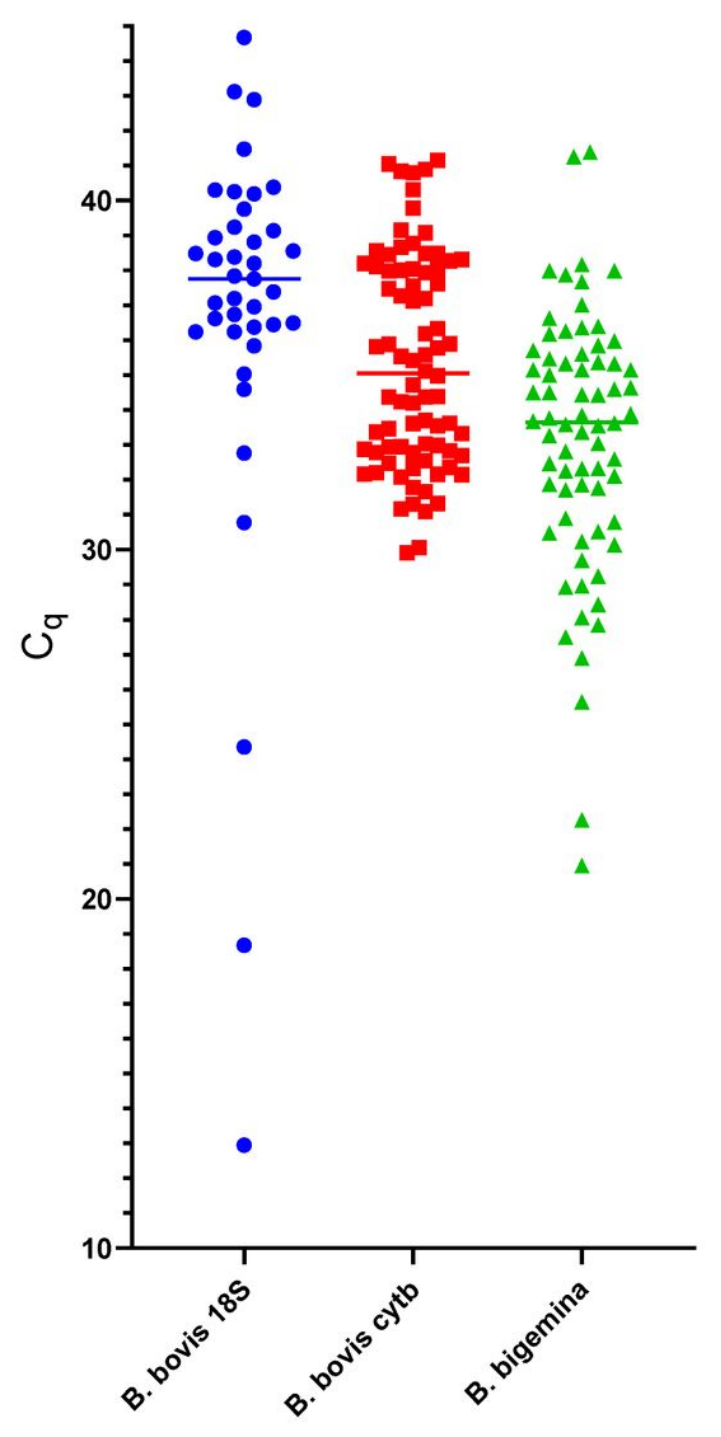

\section{Figure 3}

A scatter plot showing the range distribution of $\mathrm{B}$. bovis and $\mathrm{B}$. bigemina $\mathrm{Cq}$ values detected by the Taqman probes used in this study. $\mathrm{A}$ total of 39 and 81 blood samples were found to be positive for B. bovis by the $18 \mathrm{~S}$ and cytochrome b assays respectively. The B. bigemina cytochrome b detected 70 positive bloods. The lowest Cq value was 12.95 and 29.91 for $18 \mathrm{~S}$ and cytochrome b while the maximum was 44.68 and 41.16 respectively. The lowest Cq for $\mathrm{B}$. bigemina was 20.96 and the highest was 41.38. Mean Cq value was 36.55 (SD \pm 5.995 ) for $18 S$ and 35.37 (SD \pm 2.997 ) for $B$. bovis cytochrome b while it was 33.15 (SD \pm 3.766 ) for B. bigemina. 


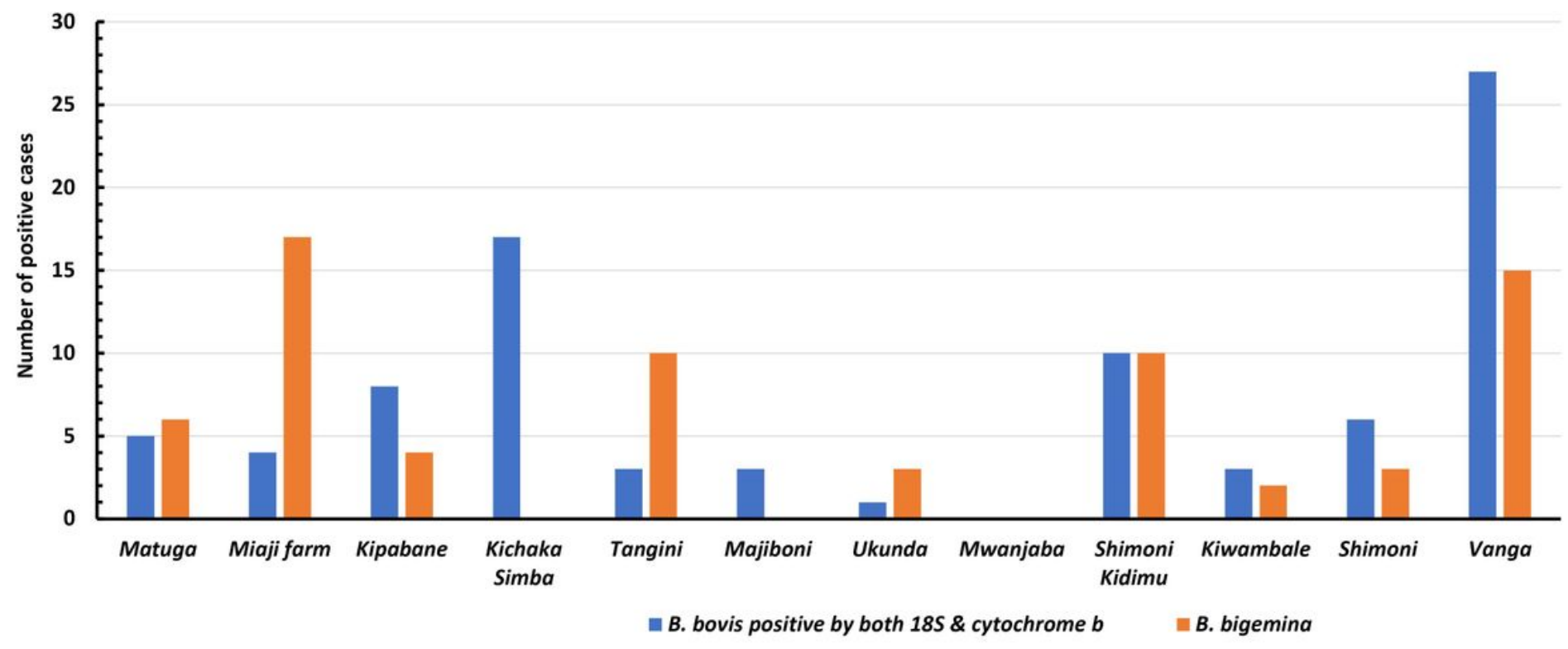

\section{Figure 4}

Distribution of Babesia bovis and B. bigemina positive blood across sampled sites

\section{Supplementary Files}

This is a list of supplementary files associated with this preprint. Click to download.

- AdditionalfileTableS1.docx

- B.bovisGraphicAbstract.pdf 